\title{
Labour Market Reform and the Effectiveness of Monetary Policy in EMU
}

\author{
Andrew Hughes Hallett \\ Vanderbilt University and CEPR \\ Nicola Viegi \\ University of Strathclyde
}

\begin{abstract}
This paper analyses the interaction between a common monetary policy and differentiated labour market institutions. We develop a model of a two country monetary union. In each country, labour markets are distinguished by the degree of centralisation in wage bargaining. In each country the government can also use an instrument (general taxation or payroll taxes) to influence their overall labour costs. Finally a common monetary policy is followed in a "conservative" manner, as defined by Rogoff (1985). The results show structural and preference asymmetries matter, both in the determination of economic policy and in performance. In particular, centralised labour market institutions confer a certain comparative advantage in policy making which provides a natural incentive for the less flexible (or less reformed) to want to join a currency union; and also for the more flexible to stay outside. This lowers the incentives for reform inside the union, as Calmfors and others have conjectured.
\end{abstract}

- JEL Classifications : E58, E61, F33, J51

- Key words : Monetary union, Labour market institutions, Asymmetries

\footnotetext{
*Corresponding address: Professor A. Hughes Hallett, Department of Economics, Vanderbilt University, Nashville, TN 37235, USA, Tel 615-322-3582, E-mail: a.hugheshallett@vanderbilt.edu, Professor N. Viegi, University of Strathclyde, Economics Department, 100 Cathedral Street, Glasgow, G4 0LN: Tel 0141548-3869, Fax 0141-552-5589 E-mail: nicola.viegi@strath.ac.uk

(C)2003-Center for International Economics, Sejong Institution, All Rights Reserved.
} 


\section{Introduction}

Economic performance in the European Monetary Union has been disappointing. It appears to be caught between the desire to exploit the economies of greater integration, as defined in the Optimal Currency Area literature, and the greater costs or adjustment difficulties which appear when there are differences in economic institutions and economic behaviour. These differences are important when it comes to assessing which policy framework will be more capable of providing macroeconomic stability in each member state.

This paper analyses the interaction between a common monetary policy and differentiated labour market institutions. These interactions are particularly important given that the policy framework established in EMU assigns a central role to labour markets for creating more flexible and responsive national economies at a microeconomic level. But because EMU will be characterised by a continued emphasis on fiscal discipline, and because the constraints at the national level have not been supplemented by an explicit system for co-ordinating national economic policies, the only effective "policy instruments" remaining at the national level are labour market reforms.

To analyse these issues, we develop a model of a two country monetary union. In each country, different labour market institutions are distinguished by the degree of centralisation in wage bargaining. In each country the government can also use an instrument (general taxation or payroll taxes) to influence overall labour costs. Finally a common monetary policy is followed in a "conservative" manner, as defined by Rogoff (1985). We then compare three regimes. In one of them the labour market is fully centralised in all countries. In this case the results depend heavily on the distance between the trade unions, central bank and fiscal authorities in terms of their preferences, since the existence of wage bargaining power creates a role for labour market policies as part of the overall policy mix.

In a fully decentralised labour market, by contrast, the responsibility for achieving national objectives will be shifted totally towards fiscal policy since wages will simply clear the market. This scenario therefore shows the possibility for conflicts between, and the need for co-ordination between, monetary and fiscal policies.

In a third scenario we analyse a situation in which there are asymmetric labour market structures. The analysis shows that a fully centralised labour market defacto provides an extra instrument of economic policy for the country that has centralised wage bargaining. That extra instrument can be used to respond 
asymmetrically to symmetric or asymmetric shocks - in addition to whatever is being done with fiscal policy. Since that option may not be open to the second country, a country with decentralised labour markets would have to produce more active fiscal policies for its own domestic stabilisation, increasing the possibility of conflict with the monetary policy objectives and between countries as it does so. The result, one might suppose, would be worse outcomes for one, if not both countries. Our analysis therefore shows one way in which structural asymmetries matter; and also that, in the presence of such asymmetries, greater coordination between economic policies may be necessary if we are to achieve macroeconomic stability.

Others have looked at the general question of how a monetary union might affect wage bargaining and hence market flexibility and performance. Recent papers of this kind include Cukierman and Lippi (2001), Sibert and Sutherland (2000), Grüner and Hefeker (1999), or Soskice and Iverson (1998). But in each case the market structures have been kept fixed; and none of these papers has asked the question of what incentives actually exist for reforming the labour markets.

In this paper we focus on that question directly: given monetary union, how might different market structures and/or different degrees of market flexibility affect economic performance in the member countries? This is an important issue because it allows us to explore what incentives may (or may not) exist for undertaking structural reforms in Europe's labour markets. ${ }^{1}$ There is some consensus that such reforms are necessary - but none, it seems, on whether they are likely or what the outcomes would be. Calmfors $(1998,2001)$ argues that such reforms are unlikely to happen; but Sibert (1999) and Sibert and Sutherland (2000) suggest they are more likely to happen than not. To some extent, we can resolve that disagreement by focussing on the different incentives involved. We show that a lack of reform is actually more likely, at least if there are some asymmetries between labour market structures when you start. This applies irrespective of the fiscal and monetary policy arrangements, and whatever the number of unions or the inflation aversion of those unions. In that regard we generalise on earlier work.

\footnotetext{
${ }^{1}$ It has long been argued that structural reforms in the labour markets are necessary for a successful EMU (Delors Committee, 1989). That argument has been based mainly on empirical and analytic evidence of a negative relationship between real wage rigidities and economic performance: Bruno and Sachs (1985), Nickell (1997). What matters therefore, is whether those rigidities are likely to get removed by monetary integration; or whether they are more likely to get preserved or extended. This paper shows that the latter is more likely. For other studies which support this point of view, see Agell (1999); Van Bergeijk (1999), or Krueger (2000).
} 


\section{The Model}

\section{A. Our Point of Departure}

Structural asymmetries are only relevant if the currency union does not produce structural convergence at a reasonable speed. Some have argued that convergence may come about because economic structures are endogenous (Frankel and Rose, 1998). In that connection, Anderson et al (2000) have found that monetary integration in Europe has been changing labour market structures and inducing wage convergence, albeit on a fairly small scale. A recent paper by Hughes Hallett and Piscitelli (2002) however, points out that business cycle models imply integration may have the opposite effect: it will promote greater convergence among economies that are small and stable, that have similar industrial structures, and where little integration has taken place. But it will create divergence among economies that are more volatile than the rest of the group, or where a lot of integration and trade dependence is already in place.

On the other hand, the strategic arguments point to continued rigidities. Calmfors $(1998,2001)$ argues that, although money-wage flexibility may be greater within the union, labour market reforms are less likely to implemented if they are linked to a time consistency. Since monetary union has been constructed as a vehicle for solving that kind of problem, there will be less need for such reforms once inside the union - and less desire for them since governments, having lost control of monetary policy, and to some extent fiscal policies via the Stability Pact, will be limited in the instruments they may use to stabilise their own economies. This argument is also used by Burda (1998) and Riboud et al (2002) who point out that most countries have in fact adopted the least flexible labour market practices in the EU when joining. Thus, if it is not too costly in terms of performance, most governments are likely to want to retain some restrictions in their labour markets so that they can have come instruments (e.g. pay roll taxes, minimum wages, employment protection) with which to stabilize domestic employment and wages.

Against that, Sibert (1999) and Sibert and Sutherland (2000) argue that the presence of asymmetric shocks could modify this conclusion since countries will have an incentive to develop new measures to counter such shocks once the ability to adjust exchange rates has been lost. We test a proposition of exactly that kind in this paper and find that, if the replacement mechanisms lead to an asymmetry in structures, then we can get the opposite result. That then supports the Calmfors 
conjecture more than it does the Sibert-Sutherland one.

\section{B. Monetary Policy}

We start with a model with a single monetary policy which is set to fix the level of prices for the union as a whole. That policy will be derived by minimising a generic quadratic objective function, of the form:

$$
\min _{\pi} L=\frac{1}{2}\left[(\pi)^{2}+\gamma\left(y_{a}-k\right)^{2}\right]
$$

where $\gamma \geq 0$ is the relative importance, in the Central Bank's view, of stabilising output levels across the union as a whole. So $y_{a}$ is the average level of output in the union, with target value $\mathrm{k}^{2}$ :

$$
y_{a}=\frac{1}{2}\left(y_{1}+y_{2}\right)=\pi-\frac{1}{2}\left(w_{1}+w_{2}\right)-\frac{1}{2}\left(t_{1}+t_{2}\right)+\frac{1}{2}\left(e_{1}+e_{2}\right)
$$

This relationship constrains the minimisation of (1). We assume that the ECB's monetary policy controls inflation directly; that wages $\left(w_{1}, w_{2}\right)$ are set nationally on the basis of the domestic labour market institutions; and that fiscal policy variables, $\left(t_{1}, t_{2}\right)$, are defined as net tax revenues in countries 1 and 2 respectively.

So $t_{j}<0$ means a fiscal deficit in country $j$. Likewise $\left(e_{1}, e_{2}\right)$ represents the supply shocks to those two countries. Those shocks will have the usual properties of zero mean and constant variance.

This aggregate supply function is just a multicountry version of the supply function popularised in this literature by Barro and Gordon (1983), Rogoff (1985), or Alesina and Gatti (1995). Indeed since wages will be set as a function of expected inflation - the function itself depending on the labour market institutions at hand - equation (2) is simply a standard union-wide supply function, extended to include fiscal policy in the manner of Debelle and Fischer (1994). Hence $\left(\mathrm{w}_{1}+\mathrm{w}_{2}\right)$ transmits the effects of expected inflation $\pi^{\mathrm{e}}$. But, because of the timing issue described below, wages will actually be set ahead of the determination of $y_{a}$. That means $\pi^{\mathrm{e}}$ will be what the wage setters (or private sector) expect, at the

${ }^{2}$ For two different justifications for the presence of $\mathrm{k}>0$, see Persson and Tabellini (1990); and Woodford (1999). Blinder (2000), however, argues that $\mathrm{k}>0$ is a realistic interpretation of what Central Banks actually do. But notice that, if $\mathrm{k}=0$, the problem just simplifies to one of resolving a conflict between output stabilisation and inflation stabilisation, driven now by the difference in priorities at the Central Bank and fiscal authorities. All our results would go through unscathed. So $\mathrm{k}>0$ is an unimportant assumption. 
beginning of the period, for inflation at the end of that period: i.e. $\pi_{t}^{e}=E\left(\pi_{t+1} \mid I_{t}\right)$, where $I_{\mathrm{t}}$ is the information available at the start of period t. That means our supply function is, in fact, a simple variant of the New-Keynesian Phillips curve model which emphasises forward looking behaviour in wage and price setting (see Roberts, 1995). And, as such, it incorporates the microfounda-tions of monopolistic competition between firms, staggered wage-price setting of Calvo contracts, and quadratic adjustment costs. Optimal wage setting would then produce a relationship like (2); see Rotemberg and Woodford (1998). ${ }^{3}$

\section{Wages and Fiscal Policy}

Wage changes in this model represent the expected changes in production costs. We assume that wage bargainers determine their desired level of wage inflation in each of the three labour market regimes studied below; and that they do so on the basis of what they expect to be the outcomes (in terms of inflation and employment) of whatever monetary and fiscal policies the Central Bank and fiscal authorities can be expected to choose in their own interest. This means we have a hierarchical game in which independent monetary and fiscal authorities play a Nash game among themselves, while playing a Stackelberg game with respect to the wage setters. This step ensures that the Central bank is fully independent in setting its policy: instrument independence in fact. Target independence is also implied since the Bank sets its own objectives, including the relative priorities $\gamma$.

The two governments, however, may well be interested in their own output levels and the differences between them ${ }^{4}$ :

$$
y_{d}=\frac{1}{2}\left(y_{1}-y_{2}\right)=-\frac{1}{2}\left(w_{1}-w_{2}\right)-\frac{1}{2}\left(t_{1}-t_{2}\right)+\frac{1}{2}\left(e_{1}-e_{2}\right)
$$

\footnotetext{
${ }^{3}$ Note that the output variables $y_{a}$, and $y_{1}$ and $y_{2}$ in what follows, will be measured as deviations from their natural rates. Hence the signs in (2). The fiscal variables can also be converted, at some complication to the algebra, to deviations from their expected values if fiscal policy is expected to have only temporary effects (Demertzis et al, 1999). And, finally, wages will be measured in terms of their growth rates net of the long run trend in productivity growth in order to match the measurement of $y$ as a deviation from its natural rate. These definitions must be kept in mind in what follows.

${ }^{4}$ This technique of dividing the analysis up between the sums and the differences of national outputs is due to Aoki (1976). It has the advantage of distinguishing clearly the policy domains of the different actors: the ECB targets the European averages, while the national governments and national unions target the national levels. Thus, no decision maker in our story actually targets yd directly, although they may well be interested in regional convergence in practice since the inflation-output performance of the unions as a whole will be influenced by the distribution of demand as well as its level (Hughes Hallett, 2000).
} 
This expression for the difference in income levels makes clear that, if shocks are asymmetric, then asymmetries in the labour markets or in fiscal policy could be used to reduce the differences between countries.

\section{The Timing of Decisions}

The moves of our policy game are as follows: first unions, or individuals, set wages; then shocks occur; and finally monetary and fiscal authorities set their instruments in a non cooperative manner. Consequently, the ECB maximises (1) subject to (2), while the two fiscal authorities maximise their own national objective functions using their own fiscal instruments;

$$
\min _{t_{j}} L_{j}=\frac{1}{2}\left[(\pi)^{2}+\left(t_{j}\right)^{2}+\beta\left(y_{j}-k\right)^{2}\right]
$$

for $j=1,2$, subject to the same national supply functions that underlie (3). The parameter $\beta>0$ determines the importance, as the governments see it, of output stabilisation relative to inflation control or public deficit control. Minimising (1) and (4) for $j=1,2$, conditional on the wages set according to whichever labour market regime is in place, now yields a sequence of three optimal reaction functions - one for each player:

$$
\begin{gathered}
\pi=\frac{\gamma}{1+\gamma}\left[\frac{1}{2}\left(w_{1}+w_{2}\right)-\frac{1}{2}\left(t_{1}+t_{2}\right)+k-\frac{1}{2}\left(e_{1}+e_{2}\right)\right], \text { and } \\
t_{j}=\frac{\beta}{1+\beta}\left[\pi-w_{j}-k-e_{j}\right] \quad \text { for } \mathrm{j}=1,2 .
\end{gathered}
$$

Solving this system of three equations in three unknowns, we have:

$$
\pi=\frac{\gamma}{1+\gamma+\beta}\left[\frac{1}{2}\left(w_{1}+w_{2}\right)+k-\frac{1}{2}\left(e_{1}+e_{2}\right)\right]
$$

\footnotetext{
${ }^{5}$ Notice that increases in either deficit, $\mathrm{t}_{j}<0$ for $\mathrm{j}=1,2$, will increase inflation. This explains why each government, as well as the central bank, will be concerned with inflation. However to keep things simple we have assumed that both governments and the Central Bank agree on the same targets for inflation (zero) and the stabilised level of national incomes $(\mathrm{k})$. It is possible to relax those assumptions (in particular, that everyone adopts the same value of $\mathrm{k}$ ), but at the cost of complicating the expressions for the optimal decisions and obscuring the message of the paper. So we have not done it here.
} 


$$
\begin{aligned}
& t_{1}=-\frac{\beta}{1+\beta+\gamma}\left[w_{1}+k-e_{1}\right]+\frac{\beta}{1+\beta+\gamma}\left[\gamma \frac{\left(w_{1}-w_{2}\right)}{2}+\gamma \frac{\left(e_{1}-e_{2}\right)}{2}\right] \\
& t_{2}=-\frac{\beta}{1+\beta+\gamma}\left[w_{2}+k-e_{2}\right]-\frac{\beta}{1+\beta+\gamma}\left[\gamma \frac{\left(w_{1}-w_{2}\right)}{2}+\gamma \frac{\left(e_{1}-e_{2}\right)}{2}\right]
\end{aligned}
$$

The equilibrium which emerges from equations (7) - (9) therefore depends on the wage formation mechanism present in each country. We analyse our three labour market regimes next. But like others working in this area, we do not include an explicit budget constraint in our model. Instead we constrain fiscal policy by placing explicit penalties on the use of fiscal policy, see (2.4). Standard theory would then produce a feedback rule, in the context of the sequential decision making of our model, which satisfies the sufficient conditions required for long term solvency and the "cash in advance" constraint (Canzoneri et al, 2001).

\section{Regime One: Non Cooperation with Decentralised Labour Markets}

\section{A. The Optimal Policies:}

In our model workers move first, setting a one period wage contract before any shocks appear and before fiscal and monetary policies are set. However, in this regime, the labour markets are identical and atomistic. Therefore increases in nominal wages, adjusted for productivity growth, will be set such that they equal the inflation rate expected at the beginning of each period,

$$
w_{j}=\pi^{e}
$$

Assuming rational expectations, substituting equations (10) into (7), (8) and (9), and solving out, we obtain the expected rates of wage and price inflation:

$$
w_{j}=\pi^{e}=\frac{\gamma}{1+\beta} k
$$

Substituting these equilibrium values into the reaction functions of the policy makers, we obtain the actual levels of inflation and taxation for the two countries: 


$$
\begin{gathered}
\pi=\frac{\gamma}{1+\beta} k-\frac{\gamma}{1+\beta+\gamma} \frac{\left(e_{1}+e_{2}\right)}{2} \\
t_{j}=-\frac{\beta}{1+\beta} k+\frac{\beta}{1+\beta+\gamma} e_{j}+\frac{\beta}{1+\beta+\gamma}\left[\gamma \frac{\left(e_{j}-e_{i}\right)}{2}\right] \quad \mathrm{j}=1,2
\end{gathered}
$$

This will give an average level of income equal to:

$$
y_{a}=\frac{\beta}{1+\beta} k+\frac{1}{1+\beta+\gamma}\left[\frac{\left(e_{1}+e_{2}\right)}{2}\right]
$$

This is the output level targeted by the Central Bank, and is a function of the average supply shocks. The difference in output levels, however, is given by

$$
y_{d}=\frac{1+\gamma(1-\beta)}{1+\beta+\gamma}\left(\frac{e_{1}-e_{2}}{2}\right) \text {. }
$$

\section{B. Absolute vs. Relative Stabilisation}

The outcomes of this scenario show that the policy makers actually need to deal with two different stabilisation problems at once. Equations (12) and (14) show that inflation and aggregate output (employment) are subject to an absolute stabilisation problem: the larger and more similar are the domestic shocks, the more variable and difficult to control those two variables become.

Equation (15) meanwhile shows that the more similar the shocks, the smaller the differences in regional incomes and the smaller the need for regional stabilisation. But the larger and more dissimilar the shocks, the greater the relative stabilisation problem to be resolved. It would be natural then, in a world with a single monetary policy, to assign that policy to stabilising the aggregate economy $\left(\mathrm{y}_{\mathrm{a}}, \pi\right.$ and the absolute stabilisation problem); and to allocate the remaining national policies $\left(t_{1}\right.$ and $t_{2}$ ) to resolving the relative or regional stabilisation problems. However that may not always be possible. The tax reaction functions in (13) contain both absolute stabilisation terms (the term in $e_{j}$ ) and relative stabilisation terms (the term in $e_{j}-e_{i}$ ). Consequently fiscal policies can only be active, to the benefit of the domestic economy, if there are no foreign shocks $\left(e_{i} \rightarrow\right.$ $0)$ or if the foreign shocks oppose and reinforce domestic shocks $\left(e_{j}\right.$ and $e_{j}-e_{i}$. share signs), and when monetary policy is to some extent output stabilising $(\gamma \neq 0)$. 
But if the domestic shocks are small, or the differences between domestic and foreign shocks are only small, then fiscal policies would not be used for stabilisation purposes.

This model therefore supports the proposition that monetary policy should be allocated to absolute stabilisation ("Keynesian" smoothing around the cycle), and fiscal polices to regional stabilisation and certain supply side measures ${ }^{6}$. But this intuition may not always work. For example, if monetary policy suffered from too much inertia or was not responsive to output disturbances, or if the shocks are too large or reinforcing, then monetary policy may not be able to deal with the absolute stabilisation problem. In that case, fiscal policy would have to become more active to deal with two different problems at once (i.e. both relative and absolute stabilisation). But fiscal policy may not be able to do that if $e_{i}>e_{j}>0$. Or if $\mathrm{e} \approx 0$ and $\mathrm{e}_{\mathrm{i}}>0$ is large; or if the fiscal policies are constrained through the stability pact; or if $e_{j}>e_{i}$ are both significant but $\beta$ is small. To prevent instrument overload in any of these cases, policy makers will naturally want to look elsewhere for an additional instrument. Interventions in the labour market are the obvious candidate.

\section{Overall Performance:}

Performance in this regime may be evaluated through the expected loss function or welfare indicator for each country. The Central Bank's expected loss function is given by (1). This implies

$$
E(L)=\frac{\gamma(1+\gamma)}{2}\left[\frac{1}{(1+\beta)^{2}}(k)^{2}+\frac{1}{4(1+\beta+\gamma)^{2}}\left(\sigma_{1}^{2}+\sigma_{2}^{2}+2 \rho \sigma_{1} \sigma_{2}\right)\right]
$$

Meanwhile at the national level we have $y_{1}=y_{a}+y_{d}$ and $y_{2}=y_{a}-y_{d}$; and hence:

$$
\begin{aligned}
& y_{1}=\frac{\beta}{1+\beta} k+\frac{1}{(1+\beta+\gamma)} e_{1}+\frac{\gamma(1-\beta)}{(1+\beta+\gamma)}\left(\frac{e_{1}-e_{2}}{2}\right) \\
& y_{2}=\frac{\beta}{1+\beta} k+\frac{1}{(1+\beta+\gamma)} e_{2}+\frac{\gamma(1-\beta)}{(1+\beta+\gamma)}\left(\frac{e_{2}-e_{1}}{2}\right)
\end{aligned}
$$

The corresponding "generic" loss function, representing the interests of the

${ }^{6}$ See Taylor (2000). 
median voter in each country, would be ${ }^{7}$ :

$$
L P_{j}=\frac{1}{2}\left[(\pi)^{2}+\left(t_{j}\right)^{2}+\lambda\left(y_{j}-k\right)^{2}\right] \quad \mathrm{j}=1,2
$$

This implies that the welfare losses in each economy are:

$$
E\left(L P_{j}\right)=\frac{1}{2}\left[\frac{\gamma^{2}+\beta^{2}+\lambda}{(1+\beta)^{2}} k^{2}+A \sigma_{j}^{2}+B \sigma_{1}^{2}+2 C \rho \sigma_{j} \sigma_{i}\right]
$$

where

$$
\begin{gathered}
A=\left(\frac{1}{1+\beta+\gamma}\right)^{2}\left[\frac{\gamma^{2}}{4}+\frac{\beta^{2}(2+\gamma)^{2}}{4}+\frac{\lambda(2+\gamma+\gamma \beta)^{2}}{4}\right] \\
B=\left(\frac{1}{1+\beta+\gamma}\right)^{2} \frac{\gamma^{2}}{4}\left[1+\beta^{2}-\lambda(1-\beta)^{2}\right] \\
C=\left(\frac{1}{1+\beta+\gamma}\right)^{2} \frac{\gamma}{2}\left[\gamma+\beta^{2}(\gamma+2)+2 \lambda(1-\beta)(1+\gamma(1-\beta))\right]
\end{gathered}
$$

Inspection of equation (20) shows that membership of a monetary union affects the overall performance of each individual economy to the extent that each has to absorb the disturbance caused by the transmission of foreign shocks $\left(\sigma_{i}^{2}\right.$ in (20)), as well as the disturbances caused by their own shocks ( $\sigma_{j}^{2}$ in (20)). But the extent to which one has to share in that pain depends on the correlation between shocks $(\rho)$, on the monetary policy responses $(\gamma)$, and on the degree of fiscal activism $(\beta)$. Only when monetary policy is responsive to output fluctuations $(\gamma \neq 0)$, do foreign shocks, and their correlation with the domestic shocks, actually play a role.

\footnotetext{
${ }^{7}$ In this formulation $\lambda$ may be equal to $\beta$, the governments' relative priority. Or it may be equal the relative priority of the electorate's median voter: $\lambda$. Demertzis et al (1999) emphasise the importance of this distinction. But, for our purposes, the important point is that (19) represents the loss functions that emerge when individual consumers maximise their intertemporal utility and then governments aggregate those utilities in order to determine their best policy choices. The difference is only that we allow $\beta$ to differ from the median voter's $\lambda$ in order to reflect the possible differences between the governments immediate priorities and those implied by the smoothing and aggregation of consumers' utilities through the electoral process - in which $\beta$ is chosen as an optimal function of the individual consumers preferences. This is taken from Tirole's (1994) agency theory: a "multiheaded" government provides checks and balances to control the private interests of any one set of decision makers. It is also the approach taken in political science: see Clark and Hallerberg (2000).
} 


\section{Regime 2: Non Cooperation with Two Centralised Unions}

We now switch to our second regime. Monetary union is still in place, but we now assume that both countries have a single centralised union - and that national wages will be set according to the objectives of those unions. This is again a symmetric regime. Both countries have the same wage bargaining arrangements.

\section{A. Optimal Policies and Output Volatility}

Because the hierarchical structure of the game has not changed, the Central Bank and governments have the same reaction functions as before:

$$
\begin{gathered}
\pi=\frac{\gamma}{1+\gamma+\beta}\left[\frac{1}{2}\left(w_{1}+w_{2}\right)+k-\frac{1}{2}\left(e_{1}+e_{2}\right)\right] \\
t_{j}=-\frac{\beta}{1+\beta+\gamma}\left[w_{j}+k-e_{j}\right]+\frac{\beta}{1+\beta+\gamma}\left[\frac{\gamma}{2}\left(e_{j}-e_{i}\right)\right]
\end{gathered}
$$

However, centralised wage bargains now determine the wage rate at the beginning of each period. We assume that each union aims for full employment and to preserve the growth of real wages in line with productivity, as set out in the following objective function: ${ }^{8}$

$$
\min _{w_{j}} L U_{j}=\frac{1}{2} E\left[\left(w_{j}-\pi\right)^{2}+\delta\left(y_{j}-k\right)^{2}\right]
$$

Employment objectives like these translate into output stabilisation in our framework. ${ }^{9}$ So this regime is the first in which wages (or interventions in the

\footnotetext{
${ }^{8}$ See Holden (2000); Danthine and Hunt (1994). Recall that Section 2 defined (real) wages as a deviation from the long run trend in productivity growth. We could have included an additional linear term here, as Cukierman and Lippi (2001) do, of $+2 \mathrm{q}(\mathrm{w}-\pi)$ to reflect the desire for higher growth in nominal wages. But it is easy to see that such an objective function can always be reformulated as (23) where the implicit target path for real wages now becomes the trend productivity growth rate less q. So a linear penalty term is equivalent to increasing the target level of real wage increases above trend productivity by a fixed amount (assuming $\mathrm{q}<0$, as in Cukierman and Lippi). But whether this makes our trade unions more or less conservative with respect to inflation, also depends on how large $\delta$ is. And (23) also includes direct penalties on large wage increases. In that respect, (23) generalises on the Cukierman-Lippi formulation. Finally, since the taxes in this model are lump sum, the leading term of (23) represents real "take home" wages.

${ }^{9}$ We do not consider the alternative formulation of (23) in which real wages are used as a supplementary form of monetary policy. This would involve giving the unions an explicit inflation objective; or giving them an explicit opportunity and framework within which they can coordinate with the Central Bank. That is a scenario for a subsequent paper.
} 
labour market) could become an additional policy instrument. Inserting the supply equations, and solving conditional on expected values for taxes and inflation, we have the reaction functions for the unions ${ }^{10}$

$$
w_{j}=\pi^{e}-\frac{\delta}{1+\delta}\left(t_{j}+k\right)
$$

Next, substituting the three reaction functions (21) - (22) into (23) we obtain

$$
w_{j}=-\frac{\delta(1+\gamma)+\gamma(1+\delta)}{1+\delta+\beta} k
$$

That, in turn, gives the following equilibrium levels of inflation and taxation:

$$
\begin{gathered}
\pi^{*}=\frac{\gamma}{1+\gamma+\beta}\left[\left(1-\frac{\delta(1+\gamma)+\gamma(1+\delta)}{1+\delta+\beta}\right) k-\frac{1}{2}\left(e_{1}+e_{2}\right)\right] \\
t_{j}=-\frac{\beta}{1+\beta+\gamma}\left[\left(1-\frac{\delta(1+\gamma)+\gamma(1+\delta)}{1+\delta+\beta}\right) k-e_{j}\right]+\frac{\beta}{1+\beta+\gamma}\left[\frac{\gamma}{2}\left(e_{j}-e_{i}\right)\right]
\end{gathered}
$$

From these expressions it is clear that the labour market characteristics do not affect the way in which policies react to shocks. This is because wages are set before any shock occurs. In this framework therefore, wages (or more properly wage costs) represent a structural characteristic of the economy and can be used to influence economic policy only in so far as economic policy seeks to reach structural objectives - in this case represented by the parameter $\mathrm{k}$.

\section{B. Social Contracts:}

Substituting for $w_{j}, t_{j}$ and $\pi$ from (25), (26) and (27) in (2), allows us to write:

$$
y_{a}=[\Omega(1-\Phi)+\Phi] k
$$

\footnotetext{
${ }^{10}$ This reaction function could be misleading, because it implies that a centralised union would always fix real wages below the level of a fragmented labour market. This is true only if we restrict the parameter $\delta$ to be greater than 0 . If we allow $\delta<0$, we can also consider the case in which the unions try to achieve an increase in real wage, i.e. they have a target nominal wage different from the expected inflation and are not inflation averse at all. Although not strictly rational (it violates the second order conditions for a minimum in the Trade Unions loss function), this extension does not change the basic implication of our results: that monetary union increases the power associated with a large, monopolistic union. How this monopoly would be used is an open question. Varying $\delta$ allows us to consider both the case where they try to increase the real wage for their own members $(\delta \leq 0)$, and the case in which they stabilise employment in the social interest: $\delta>0$.
} 
where

$$
\Omega=\frac{\beta+\gamma}{1+\gamma+\beta}, \Phi=\frac{\delta(1+\gamma)+\gamma(1+\delta)}{1+\delta+\beta}
$$

Aggregate income may therefore be larger or smaller than with decentralised bargaining, depending on the parameter values. For example, if $\gamma$ is small and $\beta$ fairly large $(\beta>0.62), y_{a}$ will fall on average. That is the case of a conservative Central bank but liberal governments. Conversely, if $\beta$ and $\gamma$ are both small, then $y_{\mathrm{a}}$ will rise on average. Finally if $\delta$ is large enough ${ }^{11}$, meaning that the unions are strongly committed to stabilising employment rather than to the preservation of real wages, then $y_{\mathrm{a}}$ will again fall.

Similarly if $\delta>0$, which means the Trade Unions care about output stabilisation, this regime will lead to lower inflation rates and smaller fiscal deficits. In fact, $\partial E\left(t_{j}\right) / \partial \delta>0$ holds for all values of the parameters. That means that a wages policy can always be used to substitute for fiscal policy: with an extra "instrument" coming into play, output can be better stabilised using domestic policies, and the Central Bank is free to devote more effort to inflation control. This is our basis for arguing that fiscally constrained governments will have an incentive to intervene in their labour markets when it comes to employment and output stabilisation.

However, the use of wages policies does not guarantee greater fiscal discipline. More liberal governments will increase the average fiscal deficit, and make $E\left(t_{j}\right)$ more negative, if $\delta<(1+\beta) /(1+2 \gamma)$. That will happen, for example, if there is a conflict between a conservative Central Bank and relatively liberal governments, so that fiscal policy has to bear the brunt of output stabilisation. But it would not happen if the Bank is also liberal; or if the unions care about employment. Conversely, increasing conservatism in monetary policy will always increase the average deficit whatever the reactions of the unions.

\section{Overall Performance Under This Regime}

The objective function values are too complicated to analyse directly in this case. But we can evaluate them numerically. The welfare of the median voter can be obtained by substituting the three equilibrium expressions (30)-(32) into the

\footnotetext{
${ }^{11}$ i.e. if $\delta>\gamma\left(2 \beta^{2}-\gamma-2\right) /[1+2 \gamma(1-\gamma-2 \beta(\gamma+\beta))-\beta(1+\beta+2 \gamma)]$ assuming the denominator of (28) to be positive.
} 
loss function $L P_{j}$. This will therefore becomes a function only of the parameters of the model

$$
L P_{j}=L P_{j}(\lambda, \beta, \gamma, \delta, k)
$$

Numerical simulations then allow us to visualise how different parameter values affect the welfare of a representative individual, in comparison to the case of perfect decentralisation. Again we can abstract from the effects of shocks because, as noted above, the stochastic elements and shocks variances are the same in both regimes. The typical outcome of that comparison, as wage bargaining behaviour varies from the self-interested to the most socially beneficial, is given in Figure 1.

It is clear from this that centralisation produces a benefit, from welfare point of view, only if wages bargaining can be used to achieve aggregate output objectives $(\delta>0)$. Otherwise, as conjectured by Calmfors and Driffill, its power will clash with the objectives of the economic policy maker, making everybody worse off.

\section{Regime 3: Asymmetries in Labour Market Institutions or Practices - a parable of flexible vs. inflexible labour markets}

Suppose the two countries have two different wage bargaining structures. In Country 1 , a total decentralisation of bargaining produces wages equal to expected

Figure 1. The WelfareEffect of Having Centralised Trade Union

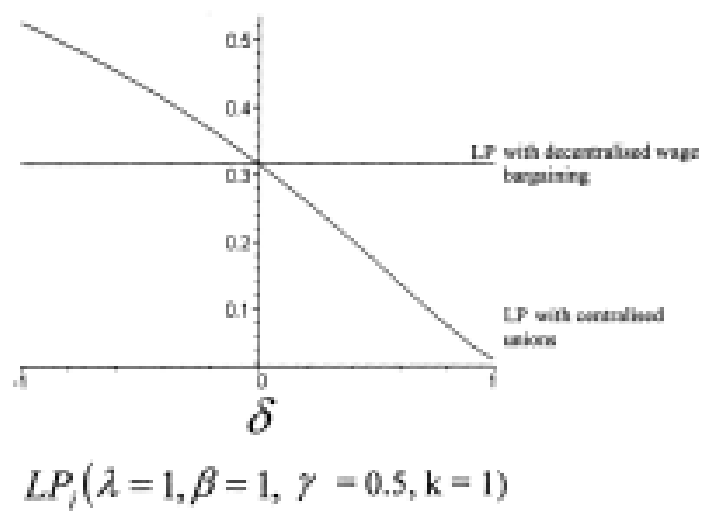


inflation. This is the economy with flexible labour markets. ${ }^{12}$ In Country 2, total centralisation in wage setting makes wages a policy instrument in the hands of the union and wages will be set according to the reaction function (25). This is the economy with the more rigid markets.

\section{A. Fiscal Policy Off}

We will develop the argument gradually. First we switch fiscal policy $\left(t_{j}=0\right)$ off to see the relationship between monetary policies and asymmetries. In the light of (13), the best way to switch the policy off is to set $\beta=0$. With $\beta=0$ in both countries, the monetary policy reaction function becomes:

$$
\pi=\frac{\gamma}{1+\gamma+\beta}\left[\frac{1}{2}\left(w_{1}+w_{2}\right)+k-\frac{1}{2}\left(e_{1}+e_{2}\right)\right]
$$

Substituting the wage formation rules (10) and (24) for countries 1 and 2 respectively into (29), we obtain:

$$
\pi=\frac{\gamma}{1+\gamma}\left[\frac{1}{2}\left(\pi^{e}+\pi^{e}-\frac{\delta}{1+\delta} k\right)+k-\frac{1}{2}\left(e_{1}+e_{2}\right)\right]
$$

and simplifying

$$
\pi=\frac{\gamma}{1+\gamma} \pi^{e}-\frac{\gamma(2+\delta)}{(1+\gamma)(2+2 \delta)} k-\frac{\gamma}{1+\gamma} \frac{\left(e_{1}+e_{2}\right)}{2}
$$

Thus, assuming rational expectations and white noise properties for the shocks we have:

$$
E \pi=\frac{\gamma(2+\delta)}{2(1+\delta)} k
$$

Substituting (31) into (30) we obtain the level of inflation as determined by the Central Bank:

\footnotetext{
${ }^{12}$ In this section we identify market flexibility with the sensitivity (or responsiveness) of wages and nonwage costs to changes to market pressures - as measured by indicators of excess demand or excess supply. The relevant indicators here are $\pi^{\mathrm{e}}$ or the output gap. Comparing (10) with (24), the centralised wage bargain contains a fixed (predetermined) component, while the coefficient on $\pi^{\mathrm{e}}$ is the same in either case. Decentralised labour markets are clearly the more flexible in this sense. This definition of market flexibility appears to be the standard one in the literature: Calmfors (1994, 1998), Danthine and Hunt (1994), Blanchard and Katz (1999), Vinals and Jimeno (2000) all use the same definition.
} 


$$
\pi=\frac{\gamma(2+\delta)}{(2+2 \delta)} k-\frac{\gamma}{1+\gamma} \frac{\left(e_{1}+e_{2}\right)}{2}
$$

From (32) one source of interaction between wage setting and monetary policies is clear. Since (32) is decreasing in $\delta$, if wage setters in country 2 care about employment, they help to reduce the political pressure on the Central Bank to satisfy the output target $\mathrm{k}$. On the other hand, given (32) and the wage equations (10) and (25), the aggregate and national aggregate supply functions will be equal to:

$$
\begin{gathered}
y_{a}=\frac{\delta}{2(1+\delta)} k+\frac{1}{1+\gamma} \frac{\left(e_{1}+e_{2}\right)}{2} \\
y_{d}=\frac{\delta}{1+\delta} k+\frac{1}{2}\left(e_{1}-e_{2}\right),
\end{gathered}
$$

implying

$$
\begin{gathered}
y_{1}=\frac{2+\gamma}{2+2 \gamma} e_{1}-\frac{\gamma}{2+2 \gamma} e_{2}, \text { and } \\
y_{2}=\frac{\delta}{1+\delta} k+\frac{2+\gamma}{2+2 \gamma} e_{2}-\frac{\gamma}{2+2 \gamma} e,
\end{gathered}
$$

Hence aggregate output is increased as long as the unions will accept that a reduction in real wages is a way to boost employment in their own country. But if they do, the differences between the national outputs will be systematically increased. We get $\mathrm{Ey}_{2}>\mathrm{Ey}_{1}$ even though there is a common monetary policy and no domestic shocks. Country 2 benefits from a permanent output expansion, while country 1 does not.

\section{B. Monetary Policy Off}

Secondly we switch off monetary policy by setting $\gamma=0$, to see the interactions between fiscal policy and the labour market. The fiscal policies become:

$$
t_{1}=-\frac{\beta}{1+\beta}\left(k-e_{1}\right)
$$

in country 1 (the one with flexible labour market), and

$$
t_{2}=-\frac{\beta}{1+\beta+\delta} k+\frac{\beta}{1+\beta} e_{2}
$$


in country 2 (the one with a less flexible labour market). Evidently the fiscal deficit will be larger in the country with the more flexible labour market, because of the term in $\delta$ in the latter. On the other hand, output will be lower in the country with larger deficits, and higher in the country with smaller deficits, because

$$
\begin{gathered}
y_{1}=\frac{\beta}{1+\beta} k+\frac{1}{1+\beta} e_{1} \\
y_{2}=\frac{\beta+\delta}{1+\beta+\delta} k+\frac{1}{1+\beta} e_{2}
\end{gathered}
$$

implies $E y_{2}>E y_{1}$. Again there are systematic differences. Country 1 will feel at a disadvantage because she has to carry the burden of the (policy) adjustments, but gets to enjoy fewer of the benefits.

\section{All Policies Active}

The reaction functions for the three policy authorities in this regime are as follows:

$$
\begin{gathered}
\pi=\frac{\gamma}{1+\gamma+\beta}\left[\frac{1}{2}\left(w_{1}+w_{2}\right)+k\right] \\
t_{1}=-\frac{\beta}{1+\beta+\gamma}\left[w_{1}+k-e_{1}\right]+\frac{\beta}{1+\beta+\gamma}\left[\gamma \frac{\left(w_{1}-w_{2}\right)}{2}\right] \\
t_{2}=-\frac{\beta}{1+\beta+\gamma}\left[w_{2}+k-e_{2}\right]+\frac{\beta}{1+\beta+\gamma}\left[\gamma \frac{\left(w_{1}-w_{2}\right)}{2}\right]
\end{gathered}
$$

in which we have set the shocks to be equal to zero, for simplicity. Substituting (39) - (41) into the wage rule for each market: ${ }^{13}$

$$
\begin{gathered}
w_{1}=\pi^{e} \\
w_{2}=\pi^{e}-\frac{\delta}{1+\delta}\left(t_{1}+k\right)
\end{gathered}
$$

Solving the resulting equations simultaneously, we have:

$$
w_{1}=-\frac{\Omega(\Theta+\Theta \Psi-2)}{2(1-\Omega-\Theta)+\Theta \Omega \Psi} k
$$

\footnotetext{
${ }^{13}$ Recall that the wage setters are the "followers" in our hierarchical game.
} 


$$
\begin{gathered}
w_{2}=-\frac{2(\Theta-\Theta \Psi-\Omega)+\Omega \Theta(\Psi-1)}{2(1-\Omega-\Theta)+\Theta \Omega \Psi} k \\
\text { and } \Omega=\frac{\gamma}{1+\gamma+\beta}, \Psi=\frac{\beta}{1+\gamma+\beta}, \Theta=\frac{\delta}{1+\delta}
\end{gathered}
$$

Then substituting (42) and (43) into the reaction functions of the policy makers and solving simultaneously, would give us the equilibrium levels of inflation, taxation and output. But looking at the complexity of expressions (42) - (43), it is clear that none of these results would give us any clear indication of what is going on. So, as before, we analyse the effect of asymmetries given a certain set of typical parameters. We choose $\lambda=1, \beta=1, \gamma=0.5, k=1$ and allow $\delta$ to vary to show the effect (on the outcomes in both countries) of different union behaviour. Figure 2 presents the welfare implications for Country 1, with flexible markets, when it has to share a monetary union with a country which has a centralised labour market and markets less flexible than its own.

Figure 2 shows that, for a country with decentralised labour market, it is almost always more costly to have to share a monetary union with a country that has more centralised wage bargaining structure. This is because the common monetary policy reacts to this asymmetry by shifting the cost of adjustment onto the country with more flexible markets and without a centralised wage bargaining structure. Only when the wage setters in the centralised economy choose to behave like the wage setters in the decentralised one, by trying only to preserve the value of their

Figure 2. Country 1: the flexible market economy. A Comparison of the Welfare Effects of Having to Share a Monetary Union with a less Flexible Economy $(\beta=\lambda)$

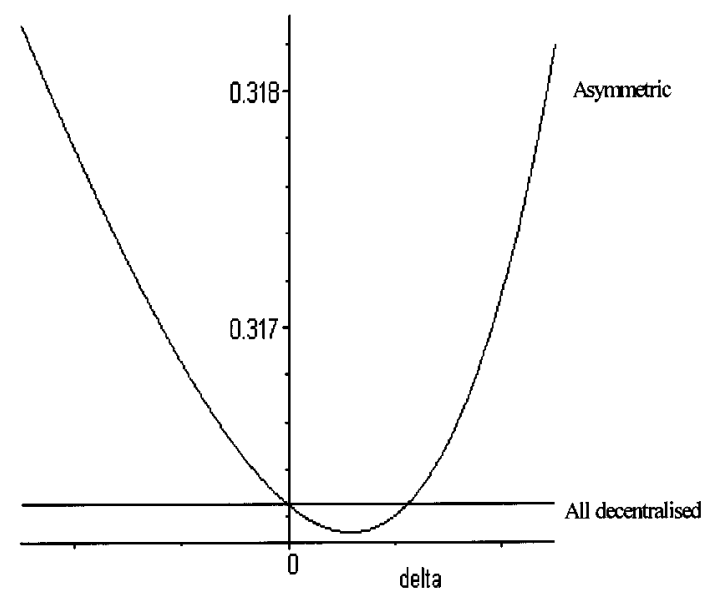


real wage $(\delta \rightarrow 0)$ for example, does the more flexible economy become indifferent to joining a monetary union of countries less flexible than itself. In all other circumstances its welfare would be higher outside the union.

Notice that the small scale on the vertical axis of Figure 2 implies that the small "gains" of the asymmetric regime (less than $0.03 \%$ ), are actually the result of rounding errors. It is easy to check that setting $\beta<\lambda$ will shift the whole parabola shaped curve up and above the horizontal line representing the losses under decentralised wage bargaining (regime 1 ). And setting $\beta>\lambda$ shifts it down, below that line. But we have set $\beta=\lambda$. The explanation is that, with $\beta<\lambda$, we can never get any gains over regime 1 because fiscal policy will never react to stabilise output as much as the representative voter would like. Hence there are always losses compared to regime 1 where wages adjust freely to stabilise output relative to inflation. In an asymmetric regime, these losses will become especially damaging if the other country has the capacity to adjust wages to make up for this loss in fiscal policy interventions (i.e. when $\delta$ is large in the other country), since not only will the other country have more stable output and lower fiscal deficits; monetary policy will also have to adjust to reduce output in country 1 in order to ensure that the more stable output in country 2 doesn't increase inflation for the system as a whole. And country 1 will have to carry larger fiscal deficits since the spillover benefits of the fiscal interventions in country 2 will have been reduced (since fiscal interventions there will be smaller). As a result, $\mathrm{Ey}_{2}>\mathrm{Ey}_{1}$ and $\mathrm{Et}_{1}$ $<\mathrm{Et}_{2}<0$ as we saw earlier.

\section{Some Political Economy Implications}

Hence Figure 2 is another way of saying that the more flexible economy will have to carry a greater proportion of the burden of adjustment, but will enjoy a smaller proportion of the benefits, if it joins a union of unreformed or more "rigid" economies. But, if fiscal policy were to become more flexible, $\beta>\lambda$ so that the parabola moves down, that extra degree of adjustment can always be supplied without loss to the other targets - and gains will show up for country 1 , even in the asymmetric regime, provided that $\delta$ doesn't get too large in the other country.

The upshot of these results is that a country with flexible markets would only want to join a monetary union that consists of countries whose markets are at least as flexible as its own. But, by the same argument, the less flexible country (country 2) would like the more flexible one (country 1) to join. In fact Figure 3 shows that country 2 would be indifferent to having a more flexible country join 
Figure 3. Country 2, the rigid market economy. A comparison of the welfare implications of having to share a monetary union with a more flexible economy.

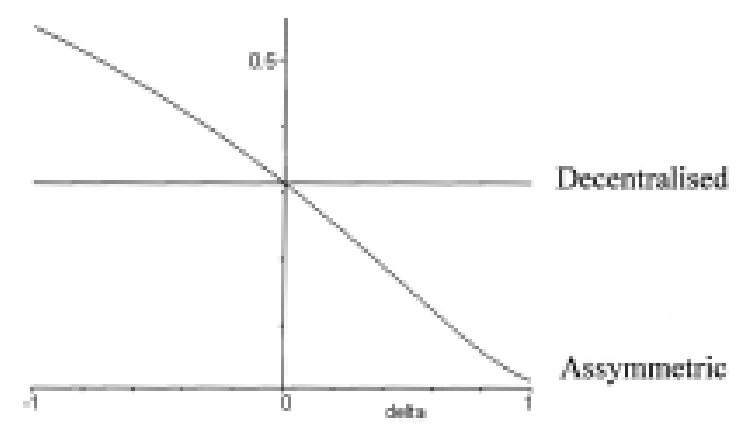

the union only if the wage bargainers in country 2 did not care about output and employment objectives. If they do care about those targets $(\delta \rightarrow 1)$, then they would like country 1 to join. In other words, a country with less flexible markets would only be prepared to accept new members with more flexibility than themselves, but not those with less. Similarly, more flexible countries would only be prepared to join a union with markets as flexible as their own. Hence those most eligible may not wish to; and those most willing to join may be the least welcome.

This result has the following, awkward implication. If a monetary union is nevertheless formed, a joining country with decentralised or flexible labour markets has no incentive to retain those characteristics once it is a member. If we compare country 1's expected losses if it is centralised as well (regime 2), with its expected losses if it remains decentralised in an asymmetric union (regime 3), we find that its welfare will improve if it moves to having centralised and less flexible markets.

Hence, if there is no incentive to decentralise to more flexible labour and product markets, this analysis actually explains why it is that most countries have in fact been reluctant to liberalise their markets, despite the competitive pressures generated by a common currency and a single market. In other words, our results demonstrate:

(a) that Calmfors' original conjecture, that monetary union is unlikely to increase labour market reform in Europe, is actually correct;

(b) that countries with more flexible economies, such as the UK or Denmark, would have found good reason not to join. That contrasts with, say, France and Germany who share broadly similar labour market characteristics and would find 
little difficulty in joining.

\section{Conclusions}

(1) Asymmetries matter. Countries with more flexible labour markets will face costs in joining a union with less flexible markets.

(2) Countries with less flexible markets face a positive incentive to form unions with, or accept new members from, those who have more flexible markets than their own.

(3) But once in the union, there is no incentive to make the labour market more flexible. In fact the incentive is to make them less flexible, up to the level of the least flexible in the union, since this allows national policy makers to bring in labour market policies an extra policy instrument to replace that lost to the common monetary policy. As Krueger (2000) says, countries will want to maintain distinct labour practices so long as they can bear the costs of those practices.

\section{Acknowledgement}

We are grateful for helpful comments from George Agiomirgianakis, but retain responsibility for any remaining errors.

Received 26 May 2002, Accepted 18 March 2003

\section{References}

Agell, J. (1999) "On the Benefits from Rigid Labour Markets : Norms, Market Failures and Social Insurance" Economic Journal, 109, F143-64.

Alesina, A. and R. Gatti (1995) "Independent Central Banks: Low Inflation at No Cost" American Economic Review, 85, 196-200.

Anderson, T. M., N. Haldrup and J. Sorensen (2000) "Labour Market Implications of EU Product Market Integration" Economic Policy, 30, 107-33.

Aoki, M (1976) "Optimal Control and Systems Theory in Dynamic Economic Analysis" North Holland, Amsterdam.

Barro, R. and D. Gordon (1983) "A Positive Theory of Monetary Policy in a Natural Rate Model” Journal of Political Economy, 91, 589-610.

Blanchard, O. and L. Katz (1999) "Wage Dynamics: Reconciling Theory and Evidence", American Economic Review, 89, 69-74. 
Blinder, A. (2000) "Central Bank Credibility: Why do we care? How do we build it? American Economic Review, 90, 1421-31.

Bruno, M and J. Sachs (1985) "The Economics of World Wide Stagflation" Basil Blackwell \& Co., Oxford.

Burda, M. (1998) "The Conferences of EU Enlargement for Central and Eastern European Labour Markets" European Investment Bank Papers, 3, 65-82.

Calmfors, L. (1994) "Centralisation of Wage Bargaining and Macroeconomic Performance: a survey" OECD Economic Surveys, 21, 159-91.

Calmfors, L. (1998) "Macroeconomic Policy, Wage Setting and Employment - What difference does the EMU make?", Oxford Review of Economic Policy, 14, 125-151.

Calmfors, L. (2001) "Unemployment, Labour Market Reform, and Monetary Union" Journal of Labour Economics, 19, 265-289.

Calmfors, L. and J. Driffill (1988) "Bargaining Structure, Corporatism, and Macroeconomic Performance" Economic Policy, 6, 14-61.

Canzoneri, M., R Cumby and B. Diba (2001) "Is the Price Level Determined by the Needs of Fiscal Solvency?" American Economic Review, 91, 1221-38.

Clark, W. and M. Hallerberg (2000) "Mobile Capital, Domestic Institutions and Electorally Induced Monetary and Fiscal Policy" American Political Science Review, 94, 323-46.

Cukierman, A. and F. Lippi (2001) "Labour Markets and Monetary Union - a strategic analysis" Economic Journal, 111, 541-565.

Danthine, J. and J. Hunt (1994) "Wage Bargaining Structure, Employment and Economic Integration" Economic Journal, 104, 528-42.

Debelle, G. and S. Fischer (1994) "How Independent Should the Central Bank Be?" in J. Fuhrer (ed) "Goals, Guidelines and Constraints Facing Monetary Policy Makers" Federal Reserve Bank, Boston, MA.

Delors Committee (1989) "Report on Economic and Monetary Union in the European Community" Office of the Publications of the European Communities, Luxemburg.

Demertzis, M., A. Hughes Hallett and N. Viegi (1999) "An Independent Central Bank faced with Elected Governments" Discussion Paper 2219, Centre for Economic Policy Research, London. (forthcoming in the European Journal of Political Economy).

Frankel, J. and A. Rose (1998) "The Endogeneity of the Optimum Currency Area Criterion" Economic Journal, 108, 1009-25.

Grüner, H. and C. Hefeker (1999) "How will EMU affect inflation and unemployment in Europe?" Scandinavian Journal of Economics, 101, 33-47.

Holden, S. (2000) "Monetary Regimes and the Coordination of Wage Setting" Department of Economics, University of Oslo, Norway (mimeo)

Hughes Hallett, A. (2000) "Aggregate Phillips Curves are not Always Vertical : Heterogeneity and Mismatch in Multiregion or Multisector Economies" Macroeconomic Dynamics, 4, 534-46

Krueger, A. (2000) "From Bismark to Maastricht: the March to European Union and the 
Labour Compact" NBER working paper 7456, Cambridge, MA.

Nickell, S. (1997) "Unemployment and Labour Market Rigidities : Europe vs North America" Journal of Economic Perspectives", 55-74.

Persson T, and Tabellini G. (1990) "Macroeconomic Policy, Credibility and Politics" Harwood Academic Publishers, Amsterdam Riboud, M., C. Sancha-Paramo and S Silva-Jauregui (2002) "Does Euroscelorosis Matter? Institutional Reform and Labour Market Performance in Central and Eastern Europe in the 1990s" WP 0202, World Bank, Washington DC.

Roberts, J. M. (1995) "New Keynesian Economics and the Phillips Curve" Journal of Money Credit and Banking, 27, 975-84.

Rogoff, K. (1985) "The Optimal Degree of Commitment to an Intermediate Monetary Target" Quarterly Journal of Economics, 99, 1169-1189.

Rotemberg, J. and M. Woodford (1998) "An Optimisation Based Econometric Framework for the Evaluation of Monetary Policy" NBER Technical Paper 233, NBER, Cambridge, MA.

Sibert, A. (1999) "Monetary Integration and Economic Reform" Economic Journal, 109, 78-92.

Sibert, A. and A. Sutherland (2000) "Monetary Regimes and Labour Market Reform" Journal of International Economics, 51, 421-35.

Soskice, D. and T, Iverson (1998) "Multiple Wage Bargaining Systems and the Single European Currency Area" Oxford Review of Economic Policy, 14, 110-24.

Taylor, J. (2000) "Reassessing Discretionary Fiscal Policy" Journal of Economic Perspectives, Vol. 14, no. 3, Summer 2000, 21-36.

Tirole, J. (1994) "The Internal Organisation of Government" Oxford Economic Papers, 46, 1-29.

Van Bergeijk, P., J Van Sinderen and B Vollaard (1999) "Structural Reform: the issues" in P. Van Bergeijk, J. van Sinderen and B Vollaard (eds)" Structural Reform in Open Economies : a road to success?" Edward Elgar, London.

Vinals, J. and J. Jimeno (2000) "The Impact of EMU on European Unemployment" Working Paper 34, Austrian National Bank, Vienna.

Woodford (1999) "Inflation Stabilisation and Welfare" Department of Economics, Princeton University (mimeo). 